\title{
Novel phase of beryllium fluoride at high pressure
}

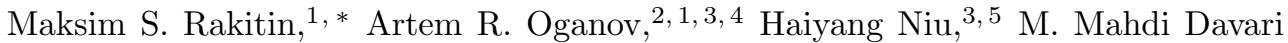 \\ Esfahani, ${ }^{1}$ Xiang-Feng Zhou, ${ }^{1}$ Guang-Rui Qian, ${ }^{1}$ and Vladimir L. Solozhenko ${ }^{6}$ \\ ${ }^{1}$ Department of Geosciences, State University of New York, Stony Brook, NY 11794, USA \\ ${ }^{2}$ Skolkovo Institute of Science and Technology, Skolkovo Innovation Center, Bldg. 3, Moscow 143026, Russia \\ ${ }^{3}$ Moscow Institution of Physics and Technology, 9 Institutskiy Lane, \\ Dolgoprudny City, Moscow Region 141700, Russia \\ ${ }^{4}$ School of Materials Science, Northwestern Polytechnical University, Xi'an 710072, China \\ ${ }^{5}$ Shenyang National Laboratory for Materials Science, Institute of Metal Research, \\ Chinese Academy of Sciences, Shenyang 110016, China \\ ${ }^{6}$ LSPM-CNRS, Université Paris Nord, 93430 Villetaneuse, France
}

(Dated: August 30, 2018)

\begin{abstract}
A previously unknown thermodynamically stable high-pressure phase of $\mathrm{BeF}_{2}$ has been predicted using the evolutionary algorithm USPEX. This phase occurs in the pressure range 18-27 GPa. Its structure has $C 2 / c$ space group symmetry and contains 18 atoms in the primitive unit cell. Given the analogy between $\mathrm{BeF}_{2}$ and $\mathrm{SiO}_{2}$, silica phases have been investigated as well, but the new phase has not been observed to be thermodynamically stable for this system. However, it is found to be metastable and to have comparable energy to the known metastable phases of $\mathrm{SiO}_{2}$, suggesting a possibility of its synthesis.
\end{abstract}

PACS numbers:

\section{INTRODUCTION}

Beryllium fluoride has many applications, such as coolant component in molten salt nuclear reactors 112 , production of special glasses 3314 , manufacture of pure beryllium ${ }^{5}$, etc. Structurally, $\mathrm{BeF}_{2}$ phases are similar to the phases of $\mathrm{SiO}_{2}$ (Fig. 1): $\alpha$-quartz phase of $\mathrm{BeF}_{2}$ and $\mathrm{SiO}_{2}$ is stable from 0 to $\sim 2 \mathrm{GPa}$, and then transforms to coesite phase which persists up to $\sim 8 \mathrm{GPa}$, and then transforms to stishovite (rutile-type phase) in $\mathrm{SiO}_{2}{ }^{6}$. However, the behavior of $\mathrm{BeF}_{2}$ experimentally is not known for pressures above $8 \mathrm{GPa}$ (see Scheme 1 in Ref! $\left.{ }^{7}\right)$.

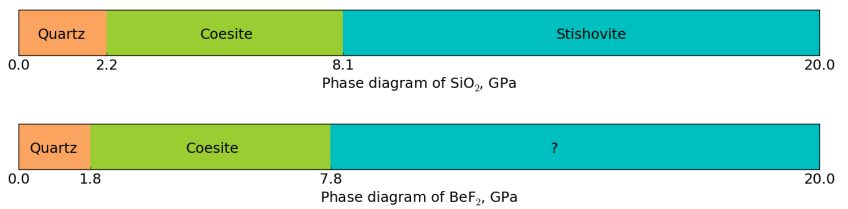

FIG. 1. Phase diagrams of $\mathrm{SiO}_{2} \sqrt{6}$ and $\mathrm{BeF}_{2}{ }^{7 \sqrt{7}}$ at low (up to room) temperatures.

One of our goals in present paper is to reveal which phase transitions can occur at higher pressures in $\mathrm{BeF}_{2}$. Beryllium compounds are extremely toxic for humans, and this limits experimentation. Computer simulation is a safe and cheap alternative to investigate such structures. In recent $a b$ initio study 8 authors explored 13 well-known $\mathrm{AB}_{2}$ structure types for their possible stability for $\mathrm{BeF}_{2}$ : $\alpha$-quartz-type $\left(P 3_{1} 21\right), \beta$-quartz-type $\left(P 6_{2} 22\right), \alpha$-cristobalite-type $\left(P 4_{1} 2_{1} 2\right), \quad \beta$-cristobalitetype $(F d-3 m)$, cubic $\mathrm{CaF}_{2}$-type $(F m-3 m), \alpha-\mathrm{PbCl}_{2}$-type $(P n m a), \mathrm{Ni}_{2}$ In-type $\left(P 6_{3} / m m c\right)$, coesite-type $(C 2 / c)$, rutile-type $\left(P 4_{2} / m n m\right)$, baddeleyite-type $\left(P 2_{1} / c\right), \alpha$ -
$\mathrm{PbO}_{2}$-type $(\mathrm{Pbcn}), \alpha$-CaCl${ }_{2}$-type $(P n n m)$ and pyritetype $(P a-3)$ structures. They found that the sequence of pressure-induced phase transitions of $\mathrm{BeF}_{2}$ up to $50 \mathrm{GPa}$ is as follows: $\alpha$-quartz-type $\stackrel{0.59 \mathrm{GPa}}{\longrightarrow}$ coesitetype $\stackrel{6.47 \mathrm{GPa}}{\longrightarrow}$ rutile-type $\stackrel{24.94 \mathrm{GPa}}{\longrightarrow} \alpha-\mathrm{PbO}_{2}$-type structures. Although $\mathrm{BeF}_{2}$ under pressure has been theoretically investigated by $\mathrm{Yu}$ et al $\stackrel{8}{\text {, }}$, we revisit these results to check for previously unknown structure(s), and we explore the relevance of these findings for $\mathrm{SiO}_{2}$.

\section{COMPUTATIONAL DETAILS}

Computer simulations of $\mathrm{BeF}_{2}$ and $\mathrm{SiO}_{2}$ has been performed in two steps: (1) prediction of a new structure of $\mathrm{BeF}_{2}$ using USPEX evolutionary algorithm; (2) calculation of properties of $\mathrm{BeF}_{2}$ and $\mathrm{SiO}_{2}$ in the wide range of pressures from 0 to $50 \mathrm{GPa}$ with a $1 \mathrm{GPa}$ step using DFT.

To find stable lowest-energy crystals structures, we performed fixed-composition search of the $\mathrm{BeF}_{2}$ system at different pressures $(15,20$ and $25 \mathrm{GPa})$ using the USPEX code ${ }^{9}$ 11] in conjunction with first-principles structure relaxations using density functional theory (DFT) within the Perdew-Burke-Ernzerhof (PBE) generalized gradient approximation (GGA) ${ }^{12}$, as implemented in the VASP package ${ }^{13}$. We employed projector augmented wave (PAW) $)^{14}$ potentials with 2 valence electrons for Be and $7-$ for $\mathrm{F}$. The wave functions were expanded in a plane-wave basis set with the kinetic energy cutoff of $600 \mathrm{eV}$ and $\Gamma$-centered meshes for Brillouin zone sampling with reciprocal space resolution of $2 \pi \times 0.10 \AA^{-1}$.

We used the VASP package to carefully reoptimize the obtained structures before calculating phonons, elasticity, electronic density of states (DOS), hardness of 
$\mathrm{BeF}_{2}$ and $\mathrm{SiO}_{2}$. For these relaxations, we also used the plane-wave cutoff of $600 \mathrm{eV}$ and $k$-meshes with resolution of $0.10 \AA^{-1}$. Phonons calculations have been performed using Phonopy ${ }^{15}$ and Quantum Espresso ${ }^{16}$ codes for the relaxed structures at pressures where these structures are found to be thermodynamically stable. Hardness was calculated using 3 methods: Lyakhov-Oganov mode ${ }^{17}$ based on the strength of bonds between atoms and bond network topology, Chen-Niu model ${ }^{18}$ which uses elastic constants obtained from DFT calculations and Mukhanov-Kurakevych-Solozhenko thermodynamic model of hardness 19 .

\section{RESULTS AND DISCUSSION}

USPEX allowed us to find a new structure of $\mathrm{BeF}_{2}$, stable at 18-27 GPa (Fig. 2). The structure has $C 2 / c$ space group and contains 12 formula units in the Bravais cell ( 6 in the primitive cell) with $a=8.742 \AA, b=8.695 \AA$, $c=4.178 \AA$ and $\beta=66.1^{\circ}$ (at $20 \mathrm{GPa}$ ). Calculated density of this new $C 2 / c$ phase is $4.2 \%$ higher than density of coesite phase, both at $20 \mathrm{GPa}$. For reference, here are lattice parameters for $\mathrm{BeF}_{2}$-stishovite at $30 \mathrm{GPa}$ : $a=b=3.986 \AA, c=2.501 \AA$ and $\alpha=\beta=\gamma=90^{\circ}$. The value of the bulk modulus $B_{0}=22.4 \mathrm{GPa}$ of the $C 2 / c$ structure of $\mathrm{BeF}_{2}$ with its pressure derivative $B_{0}^{\prime}=3.9$ was obtained from a least-squares fit using the Murnaghan equation of state $^{20}$ (Fig. 3). The zero-pressure unit cell volume was taken as $V_{0}=213.7 \AA^{3}$.
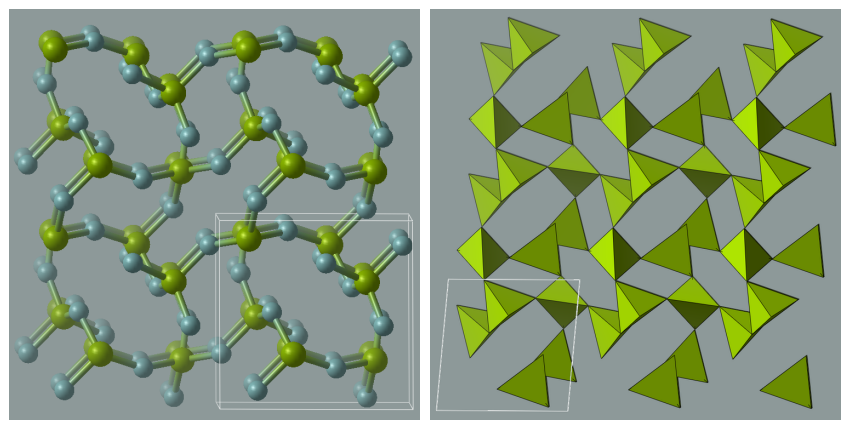

FIG. 2. $C 2 / c$ structure of $\mathrm{BeF}_{2}$, stable at $18-27 \mathrm{GPa}$.

\section{A. Thermodynamic stability}

We have calculated the enthalpies of $\alpha$-quartz $\left(P 3_{2} 21\right)$, coesite $(C 2 / c)$, coesite-II $(C 2 / c)$, stishovite $\left(P 4_{2} / m n m\right)$, $\alpha$ - $\mathrm{PbO}_{2}$-type $(\mathrm{Pbcn})$ structure and our new structure $(C 2 / c)$ for both $\mathrm{BeF}_{2}$ and $\mathrm{SiO}_{2}$ at different pressures from 0 to $50 \mathrm{GPa}$ with a $1 \mathrm{GPa}$ step. The results are presented in Fig. 4 .

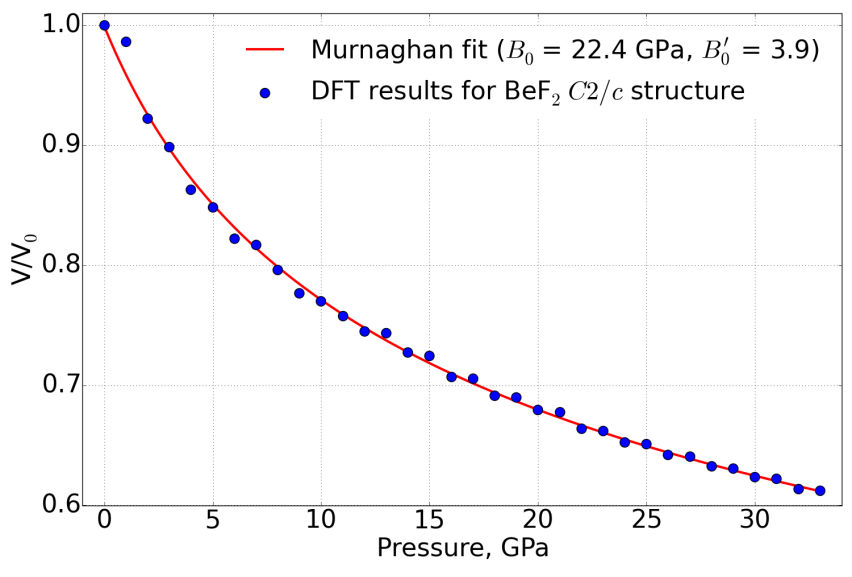

FIG. 3. Equation of state of $\mathrm{BeF}_{2} C 2 / c$ structure.

\section{1. $\mathrm{BeF}_{2}$ under pressure}

For the case of $\mathrm{BeF}_{2} \alpha$-quartz structure is stable from 0 to $4 \mathrm{GPa}$, followed by coesite structure stable from 4 to $18 \mathrm{GPa}$, and the $C 2 / c$ structure is found to be stable between 18 and $27 \mathrm{GPa}$, which then gives place to stishovite structure at higher pressures (Fig. 4(a)). We see transition from coesite-type to $C 2 / c$, then to rutile-type, but at much higher pressure (27 GPa against 6.47 GPa in Ref. ${ }^{8}$, where LDA was used). According to Demuth et al ${ }^{21}$, the LDA approximation used in Ref ${ }^{8}$ underestimates phase transition pressures, whereas using the GGA yields more reliable results. The $\alpha-\mathrm{PbO}_{2}$-type structure is not stable at any pressure (in the investigated interval from 0 to $50 \mathrm{GPa}$ ) for $\mathrm{BeF}_{2}$ (though it is close to stability at $\sim 27 \mathrm{GPa}$ ), while for $\mathrm{SiO}_{2}$ it is indeed stable at pressures above $\sim 80-90 \mathrm{GPa}^{22}$.

\section{2. $\mathrm{SiO}_{2}$ under pressure}

From Fig. 4(b) it is clearly seen that in $\mathrm{SiO}_{2}$ the transition from $\alpha$-quartz to coesite occurs at $5 \mathrm{GPa}$, followed by transformation to stishovite at $\sim 7 \mathrm{GPa}$, which continues to be stable up to $50 \mathrm{GPa}$. This phase transition sequence is in good agreement with experiments $\sqrt{6}$ and with the GGA results by Demuth et al ${ }^{[21}$, Oganov et al ${ }^{22}$ and LDA results of Tsuchiya et al. ${ }^{23}$; it is known though 21 that the GGA is more accurate than the LDA for phase transition pressures. The new structure is not stable at any pressure for $\mathrm{SiO}_{2}$, but at $0 \mathrm{GPa}$ is only $3.4 \mathrm{meV} /$ atom higher in energy than $\alpha$-quartz, and should be synthesizable as a metastable phase. Our results of coesite $\rightarrow$ coesite-II transition are in good agreement with recent study of Černok et al. $\stackrel{24}{ }$, where they observe coesite at 20.3 GPa, and after an abrupt change in the diffraction pattern between $\sim 20$ and $\sim 28 \mathrm{GPa}$ - coesite-II at 27.5 and 30.9 GPa. 


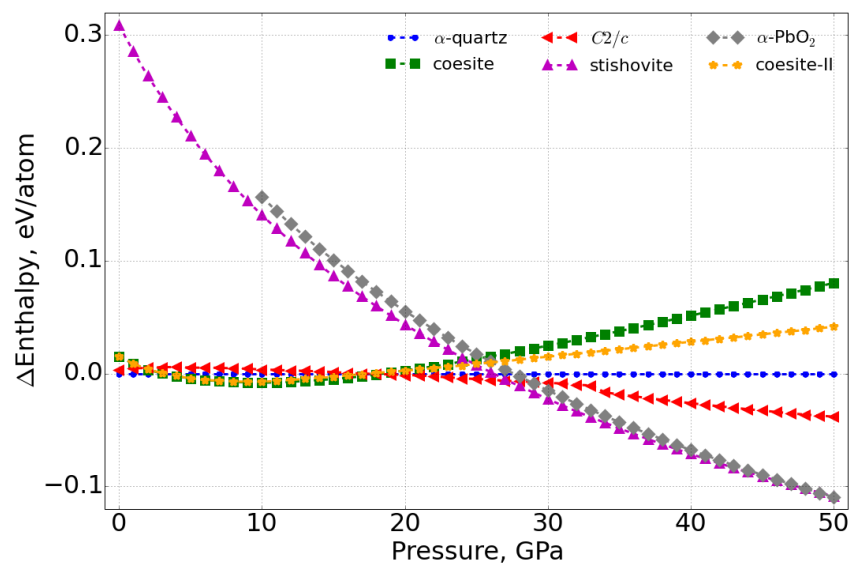

(a)

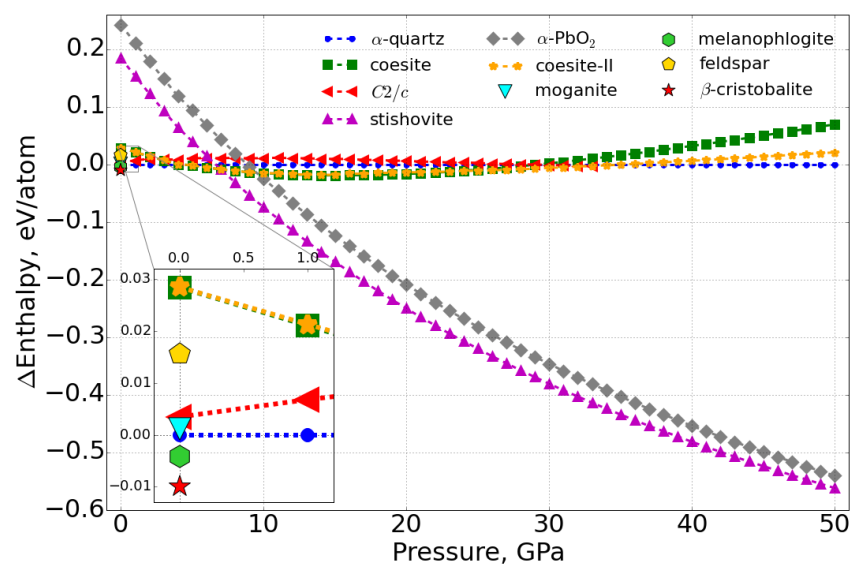

(b)

FIG. 4. Enthalpies (relative to $\alpha$-quartz) of (a) $\mathrm{BeF}_{2}$ and (b) $\mathrm{SiO}_{2}$ phases as a function of pressure.

\section{Metastable structures of $\mathrm{SiO}_{2}$}

It is well known that $\mathrm{SiO}_{2} \alpha$-quartz is thermodynamically stable at ambient pressure. However, there are numerous known $\mathrm{SiO}_{2}$ polymorphs which are metastable, but exist in nature or can be synthesized. We examined $\mathrm{SiO}_{2}$ feldspar, baddeleyite, melanophlogite and moganite at $0 \mathrm{GPa}$. El Goresy et al. ${ }^{[25}$ claimed a baddeleyitelike post-stishovite phase of silica in the Shergotty meteorite, however later that controversial phase turned out to be $\alpha-\mathrm{PbO}_{2}$-like silica ${ }^{26}$. Our calculations confirm that the baddeleyite-like form of $\mathrm{SiO}_{2}$ is very unfavorable at $0 \mathrm{GPa}$ and spontaneously (barrierlessly) transforms into the $\alpha-\mathrm{PbO}_{2}$-like structure. We have found that $\mathrm{SiO}_{2}$-feldspar, moganite and melanophlogite are energetically very close to the stable phase ( $\alpha$-quartz) and to the new $C 2 / c$ structure. Differences in enthalpy between melanophlogite, new structure and $\alpha$-quartz are less than $0.01 \mathrm{eV} /$ atom (see zoomed inset in Fig. 4(b)). The fact that complex open structure of melanophlogite (138 atoms/cell) has a slightly lower energy than $\alpha$ - quartz, can be explained by errors of the GGA, which were discussed in details by Demuth et al. ${ }^{21}$. They also found $\beta$-cristobalite (Fig. 4(b) is lower in energy by about $0.03 \mathrm{eV} / \mathrm{SiO}_{2}$ than $\alpha$-quartz, confirmed by calculations of Zhang et al. ${ }^{[27}$, showing that the GGA slightly overstabilizes low-density structures.

\section{B. Lattice dynamics}

Since the new structure of $\mathrm{BeF}_{2}$ appears to be thermodynamically stable, analysis of dynamical stability (phonon dispersion) has been performed for this structure as well as for all other structures at pressures where they were found to be thermodynamically stable. Our results show that $\mathrm{BeF}_{2} \alpha$-quartz at $0 \mathrm{GPa}$, coesite at $5 \mathrm{GPa}$, new structure at $25 \mathrm{GPa}$ and stishovite at $30 \mathrm{GPa}$ do not have imaginary frequencies. Similar results are observed for $\mathrm{SiO}_{2} \alpha$-quartz at $0 \mathrm{GPa}$, coesite at $5 \mathrm{GPa}$ and stishovite at $10 \mathrm{GPa}$. Fig. 5 shows dynamical stability of the new structure of $\mathrm{BeF}_{2}$ since no imaginary frequencies are observed in the phonon dispersion plot.

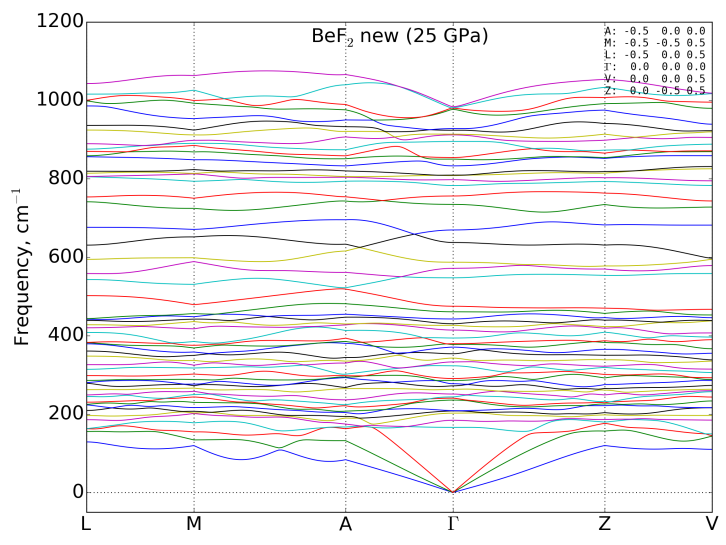

FIG. 5. Phonons dispersion curves showing dynamical stability of the $C 2 / c$ structure of $\mathrm{BeF}_{2}$ at $25 \mathrm{GPa}$.

\section{Electronic properties}

According to Fig. 6, all $\mathrm{BeF}_{2}$ phases are insulators, the DFT band gap increases from $\sim 7$ to $\sim 10 \mathrm{eV}$ with increasing pressure from 0 to $30 \mathrm{GPa}$ and the value of the gap is in good agreement with data of $\mathrm{Yu}$ et al .8 .

For $\mathrm{SiO}_{2}$ (Fig. 7) we also observe insulating behavior, and the band gap is about $6 \mathrm{eV}$ and remains almost unchanged with increasing pressure.

\section{Hardness}

Three models have been exploited to calculate hardnesses - the Lyakhov-Oganov $\sqrt{17}$, Chen-Niu $\frac{18}{\sqrt{10}}$ and 

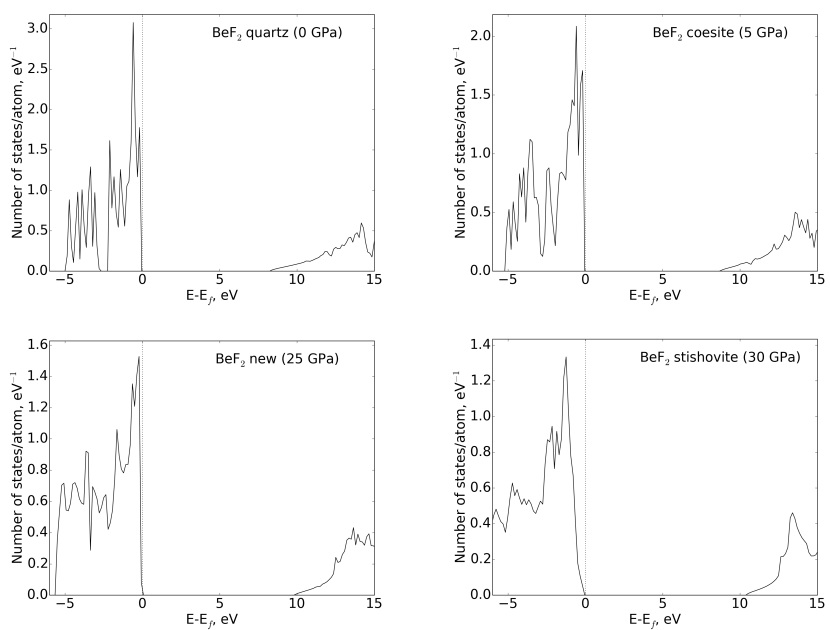

FIG. 6. Density of states of $\mathrm{BeF}_{2}$ in the $\alpha$-quartz (at $0 \mathrm{GPa}$ ), coesite (at $5 \mathrm{GPa}$ ), $C 2 / c$ structure (at $25 \mathrm{GPa}$ ), and stishovite (at $30 \mathrm{GPa}$ ) phases.

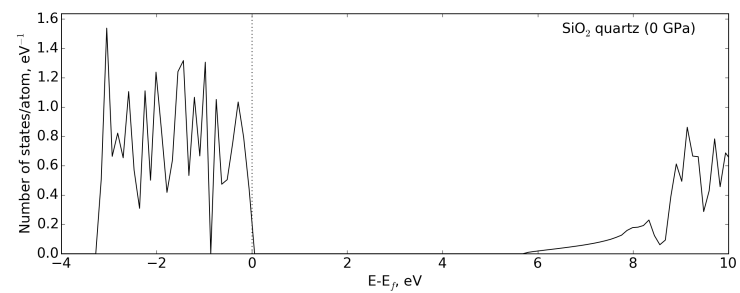

(a)

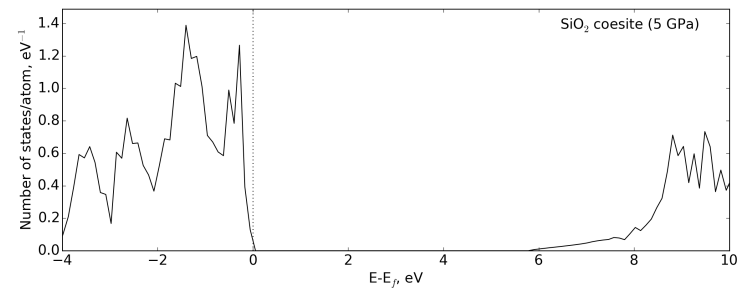

(b)

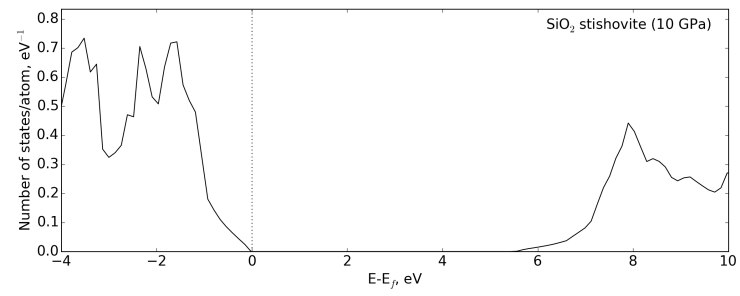

(c)

FIG. 7. Density of states of $\mathrm{SiO}_{2}$ in the (a) $\alpha$-quartz (at $0 \mathrm{GPa}$ ), (b) coesite (at $5 \mathrm{GPa}$ ) and (c) stishovite (at $10 \mathrm{GPa}$ ) phases.
Mukhanov-Kurakevych-Solozhenkd ${ }^{19}$ models. First approach is based on concepts of bond strengths and bond topology to compute hardness. Detailed description of the methodology can be found in Ref 17 . This model has been implemented in the USPEX code, and for greater convenience has also been implemented as an online utility available at http://han.ess.sunysb.edu/ hardness/. The second method of hardness calculation is Chen-Niu model, which is based on elastic tensor components and also implemented in the USPEX code. The third one is a thermodynamic model of hardness.

The results can be seen in Table I. Experimental data are provided where available - Vickers hardness of $\mathrm{SiO}_{2}-$ quartz ${ }^{28}, \mathrm{SiO}_{2}$-coesite ${ }^{19}$ and $\mathrm{SiO}_{2}$-stishovite ${ }^{29}$. From Table I it is clearly seen that the calculated hardness of $\mathrm{SiO}_{2}$ quartz and stishovite is much higher than one of $\mathrm{BeF}_{2}$ analogs. The hardness of $\mathrm{BeF}_{2}$ and $\mathrm{SiO}_{2}$ in the new $C 2 / c$ structure is comparable with the hardness of $\alpha$-quartz and coesite.

\section{CONCLUSIONS}

We have examined thermodynamic, vibrational, electronic and elastic properties of $\mathrm{BeF}_{2}$ and $\mathrm{SiO}_{2}$ phases using DFT calculations. The sequence of pressure-induced phase transitions of $\mathrm{BeF}_{2}$ up to $50 \mathrm{GPa}$ is as follows: $\alpha$ quartz-type $\stackrel{4 G P a}{\longrightarrow}$ coesite-type $\stackrel{18 G P a}{\longrightarrow} C 2 / c \stackrel{27 G P a}{\longrightarrow}$ stishovite (rutile-type) structures. We found a new phase of $\mathrm{BeF}_{2}$ which is thermodynamically stable at pressures from 18 to $27 \mathrm{GPa}$. This phase is not observed in $\mathrm{SiO}_{2}$, but could be synthesized in principle. Electronic properties analysis has shown $\mathrm{BeF}_{2}$ and $\mathrm{SiO}_{2}$ remain insulating in a wide range of pressures (from 0 to $50 \mathrm{GPa}$ ). Hardness of $\mathrm{BeF}_{2}$ and $\mathrm{SiO}_{2}$ in the new structure is comparable with hardness of $\alpha$-quartz and coesite at $0 \mathrm{GPa}$. Hardnesses of metastable $\mathrm{SiO}_{2}$ structures have been examined as well.

\section{AUTHOR CONTRIBUTIONS}

M.R., H.N. and M.D. performed the calculations, M.R. and A.R.O. contributed to the analysis and wrote the paper. X.F.Z and G.R.Q. provided technical assistance with calculations. V.L.S. proposed the idea, performed calculations of hardness and participated in the discussion.

\section{ADDITIONAL INFORMATION}

Competing financial interests: The authors declare no competing financial interests. 
TABLE I. Hardness of $\mathrm{BeF}_{2}$ and $\mathrm{SiO}_{2}$ structures at $0 \mathrm{GPa}$ in GPa. For the metastable $\mathrm{SiO}_{2}$ structures we present enthalpies relative to $\alpha$-quartz (in $\mathrm{eV}$ per formula unit).

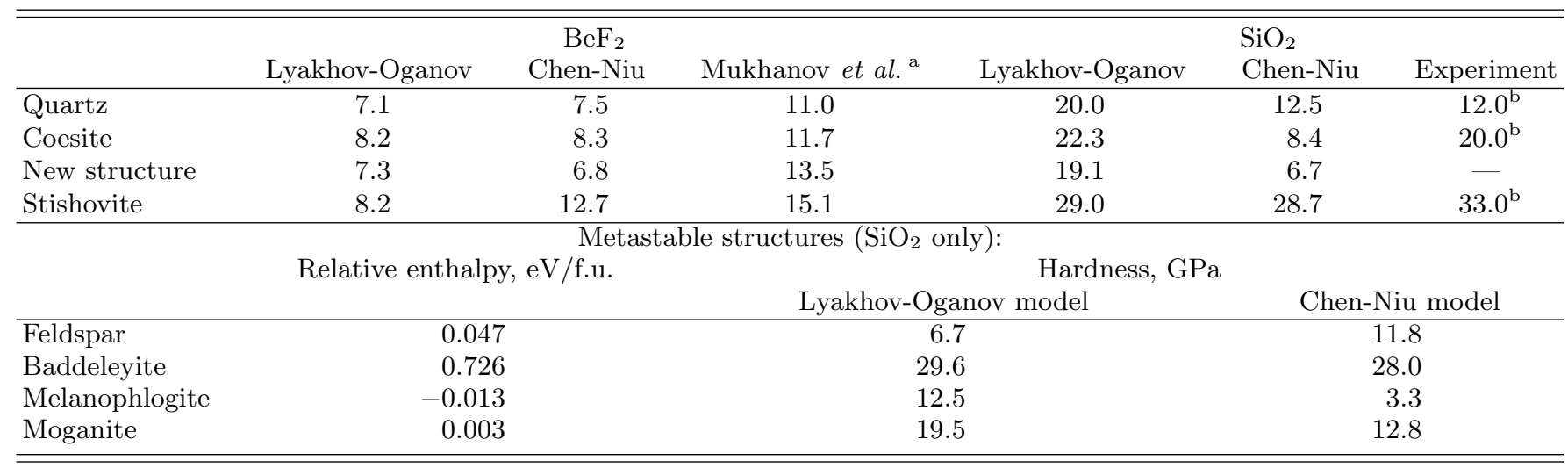

a Thermodynamic model of hardness (Ref. $\left.{ }^{[19}\right)$

b Vickers hardness

\section{ACKNOWLEDGMENTS}

We thank the National Science Foundation (EAR-1114313, DMR-1231586), DARPA (Grant No. W31P4Q1210008), the Government of Russian Federation (grant No. 14.A12.31.0003), and Foreign Talents Introduction and Academic Exchange Program (No. B08040). Also, we thank Dr. V.A. Mukhanov for valuable comments.

\section{Appendix A: Densities of $\mathrm{BeF}_{2}$ and $\mathrm{SiO}_{2}$ structures}

Table II shows densities of $\mathrm{BeF}_{2}$ structures at 0 and $20 \mathrm{GPa}$ and $\mathrm{SiO}_{2}$ structures at $0 \mathrm{GPa}$.

TABLE II. Densities of $\mathrm{BeF}_{2}$ and $\mathrm{SiO}_{2}$ structures.

\begin{tabular}{lcrr}
\hline \multicolumn{1}{c}{ System } & $\begin{array}{c}\text { Number of } \\
\text { atoms }\end{array}$ & $\begin{array}{c}\text { Volume, } \\
\AA / \text { cell }\end{array}$ & $\begin{array}{r}\text { Density, } \\
\mathrm{g} / \mathrm{cm}^{3}\end{array}$ \\
\hline $\mathbf{B e F}_{2}$ at 0 GPa: & & & \\
$\alpha$-quartz & 9 & 105.167 & 2.244 \\
coesite & 24 & 254.636 & 2.472 \\
coesite-II & 96 & 1021.960 & 2.464 \\
$C 2 / c$ & 18 & 213.696 & 2.209 \\
stishovite & 6 & 47.771 & 3.294 \\
\hline $\mathbf{B e F}_{2}$ at 20 GPa: & & & \\
$\alpha$-quartz & 9 & 73.078 & 3.230 \\
coesite & 24 & 202.001 & 3.116 \\
$C 2 / c$ & 18 & 145.159 & 3.252 \\
stishovite & 6 & 41.492 & 3.793 \\
\hline SiO ${ }_{2}$ at 0 GPa: & & & \\
$\alpha$-quartz & 9 & 116.934 & 2.580 \\
coesite & 24 & 283.341 & 2.839 \\
coesite-II & 96 & 1137.296 & 2.830 \\
$C 2 / c$ & 18 & 243.569 & 2.477 \\
stishovite & 6 & 48.185 & 4.174 \\
$\alpha$-PbO $_{2}$-type & 12 & 94.623 & 4.251 \\
\hline \hline
\end{tabular}

Appendix B: CIF file of $\mathbf{B e F}_{2} C 2 / c$ structure at $20 \mathrm{GPa}$

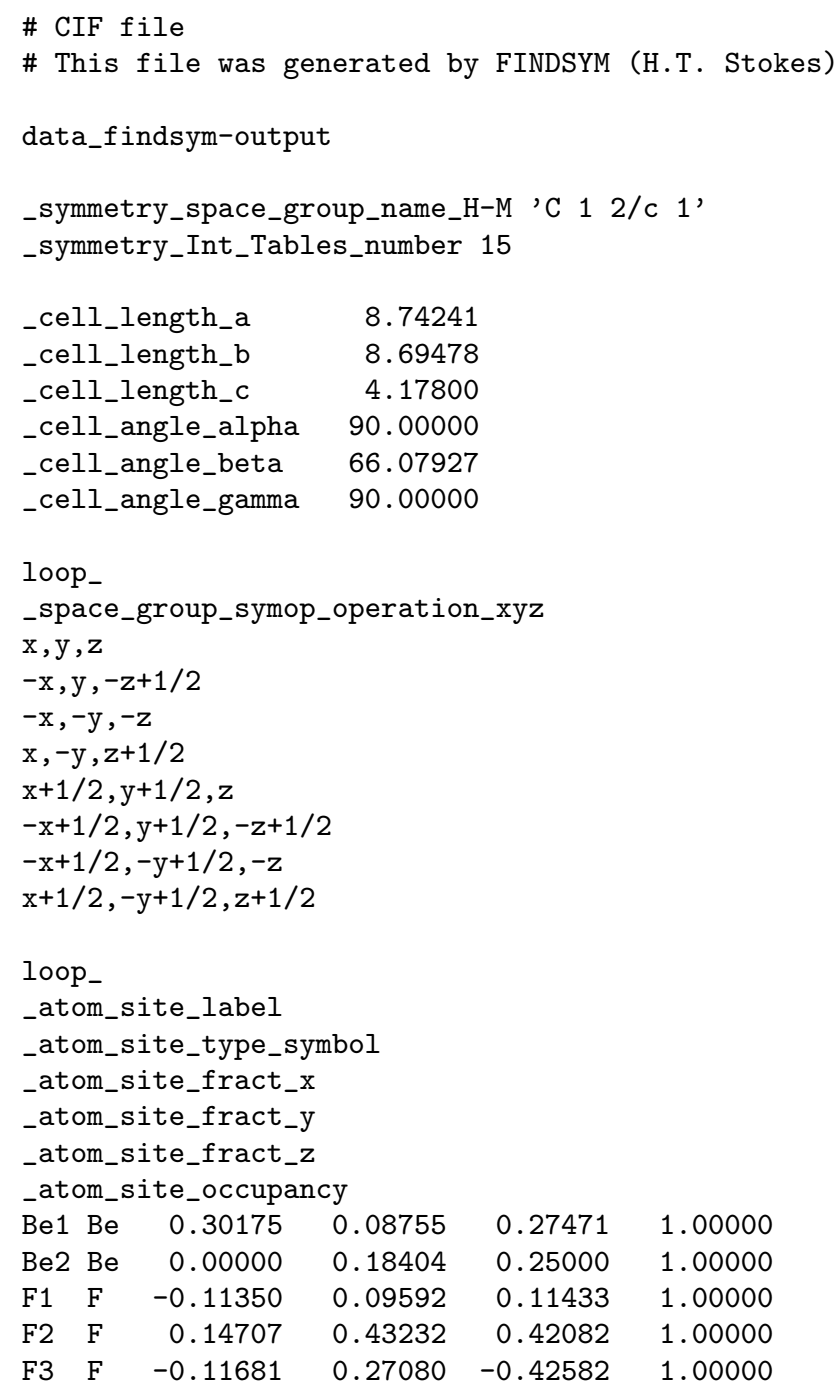


* Correspondence and requests for materials should be addressed to M.S. Rakitin (maksim.rakitin@stonybrook.edu) or A.R. Oganov (artem.oganov@stonybrook.edu)

${ }^{1}$ C. Weaver, R. Thoma, H. Insley, H. Friedman, and U. A. E. Commission, Phase equilibria in molten salt breeder reactor fuels: The system $\mathrm{LiF}_{-} \mathrm{BeF}_{2}-U \mathrm{~F}_{4}-\mathrm{Th} \mathrm{F}_{4}$ (Oak Ridge National Laboratory, 1961).

2 O. Beneš and R. Konings, Journal of Fluorine Chemistry 130, 22 (2009)

3 J. Parker and P. France, in Glasses and Glass-Ceramics, edited by M. Lewis (Springer Netherlands, 1989) pp. 156202.

4 F. Gan, Journal of Non-Crystalline Solids 184, 9 (1995).

${ }^{5} \mathrm{H}$. Hausner, Beryllium, its metallurgy and properties, edited by Henry H. Hausner (University of California Press Berkeley, 1965) p. 322.

${ }^{6}$ V. Swamy, S. Saxena, B. Sundman, and J. Zhang, Journal of Geophysical Research: Solid Earth 99, 11787 (1994)

${ }^{7}$ P. Ghalsasi and P. Ghalsasi, Inorganic Chemistry 50, 86 (2011)

${ }^{\delta}$ F. Yu, M. Xu, M. Jiang, and J.-X. Sun, Solid State Communications 169, 14 (2013)

${ }^{9}$ A. Oganov and C. Glass, The Journal of Chemical Physics 124, 244704 (2006)

io A. Oganov, A. Lyakhov, and M. Valle, Accounts of Chemical Research 44, 227 (2011).

${ }_{11}$ A. Lyakhov, A. Oganov, H. Stokes, and Q. Zhu, Computer Physics Communications 184, 1172 (2013)

${ }_{12}$ J. Perdew, K. Burke, and M. Ernzerhof, Phys. Rev. Lett. 77, 3865 (1996)

Is G. Kresse and J. Furthmüller, Phys. Rev. B 54, 11169 (1996)

${ }_{14}$ G. Kresse and D. Joubert, Phys. Rev. B 59, 1758 (1999).

15 A. Togo, F. Oba, and I. Tanaka, Phys. Rev. B 78, 134106 (2008)
16 P. Giannozzi, S. Baroni, N. Bonini, M. Calandra, R. Car, C. Cavazzoni, D. Ceresoli, G. Chiarotti, M. Cococcioni, I. Dabo, A. Corso, S. Gironcoli, S. Fabris, G. Fratesi, R. Gebauer, U. Gerstmann, C. Gougoussis, A. Kokalj, M. Lazzeri, L. Martin-Samos, N. Marzari, F. Mauri, R. Mazzarello, S. Paolini, A. Pasquarello, L. Paulatto, C. Sbraccia, S. Scandolo, G. Sclauzero, A. Seitsonen, A. Smogunov, P. Umari, and R. Wentzcovitch, Journal of Physics: Condensed Matter 21, 395502 (2009)

17 A. Lyakhov and A. Oganov, Phys. Rev. B 84, 092103 (2011)

${ }_{18}$ X.-Q. Chen, H. Niu, D. Li, and Y. Li, Intermetallics 19, 1275 (2011).

I9 V. Mukhanov, O. Kurakevych, and V. Solozhenko, Journal of Superhard Materials 30, 368 (2008)

${ }^{20}$ F. Murnaghan, Proceedings of the National Academy of Sciences 30, 244 (1944).

${ }^{21}$ T. Demuth, Y. Jeanvoine, J. Hafner, and J. Ángyán, Journal of Physics: Condensed Matter 11, 3833 (1999).

24 A. Oganov, M. Gillan, and G. Price, Phys. Rev. B 71, 064104 (2005)

${ }_{23}$ T. Tsuchiya, R. Caracas, and J. Tsuchiya, Geophysical Research Letters 31, 1 (2004)

${ }^{24}$ A. Cernok, E. Bykova, T. Ballaran, H.-P. Liermann, M. Hanfland, and L. Dubrovinsky, Zeitschrift für Kristallographie - Crystalline Materials 229, 761 (2014).

25 A. El Goresy, L. Dubrovinsky, T. Sharp, S. Saxena, and M. Chen, Science 288, 1632 (2000)

${ }^{26}$ L. Dubrovinsky, N. Dubrovinskaia, S. Saxena, F. Tutti, S. Rekhi, T. Bihan, G. Shen, and J. Hu, Chemical Physics Letters 333, 264 (2001)

27 J. Zhang, Q. Zeng, A. Oganov, D. Dong, and Y. Liu, Physics Letters A 378, 3549 (2014)

28 A. Oganov and A. Lyakhov, Journal of Superhard Materials 32, 143 (2010).

29 J. Léger, J. Haines, M. Schmidt, J. Petitet, A. Pereira, and J. da Jornada, Nature 383, 401 (1996) 